\title{
A MERCADORIA CULTURAL
}

Mário Fernando BOLOGNESI ${ }^{1}$

- RESUMO: Adorno e Horkheimer adotaram a noção de fetichismo da mercadoria para a análise da arte e da cultura. Bens materiais e físicos não são idênticos aos simbólicos. Apesar de dominante, a indústria cultural não pode ser tomada como protótipo de toda análise da cultura. Não se pode reduzir toda a produção cultural da época da economia de mercado a produtos de mercado. A pluralidade de práticas artísticas e culturais, à qual se assiste em países como o Brasil, torna problemático o uso indiscriminado do referencial frankfurtiano.

- PALAVRAS-CHAVE: Mercadoria; fetichismo; indústria cultural; bens culturais.

Dentre as várias e pertinentes contribuições de Karl Marx à crítica das condições de vida sob o capitalismo, uma delas se sobressai, especialmente porque sua conotação, embora originária da Economia Política, extrapola em muito os seus limites. Trata-se da análise da mercadoria e seu respectivo fetichismo, uma abstração e condensação das implicações inter-subjetivas da relação entre os homens, que é, em última instância, uma relação entre coisas. Ainda que a análise de Marx esteja circunscrita ao âmbito da economia, ela, pode-se dizer, encontra-se de tal forma adensada que alcança o domínio da filosofia. Nesse aspecto, a mercadoria e seu fetichismo convertem-se em uma espécie de "mônada" do capitalismo, ao lado, certamente, do conceito de luta de classes.

De onde provém essa dimensão que se sobrepõe ao trabalho humano e seus produtos, a ponto de estes tornarem-se em algo que na aparência não o são? - pergunta-se Marx. A mercadoria não é uma simples coisa; não é aquilo que aparenta ser. A aderência de valores externos faz dela a portadora de "sutileza metafísica e manhas teológicas" (Marx, 1983, p.70). E esse processo não está sedimentado no valor de uso, no destino dos produtos para a satisfação das necessidades dos homens. Essa

1 Professor do Departamento de Filosofia - UNESP - 17525-900 - Marilia - SP. 
aderência dá-se na forma mercadoria como tal, no momento em que o trabalho humano (alienado, por excelência) e seus resultados são dados para o conjunto da sociedade como mercadorias; ou seja, no valor como atributo de troca.

O fetichismo da mercadoria consiste, pois, na transformação do produto social em uma coisa metafísica. A mercadoria é fruto de relações objetivas de produção e, na economia capitalista, ela alcança o estatudo de mediação entre os produtores, porque refrata as relações sociais entre os homens como uma relação entre objetos, ou melhor, como uma relação objetiva entre coisas. ${ }^{2}$ Ela aparece então, como dotada de vida própria: torna-se independente e escamoteia a sua origem. A forma mercadoria é a síntese das relações sociais que se erigem a partir do trabalho, de tal forma que essas relações dão-se "não como relações diretamente sociais entre pessoas em seus próprios trabalhos, senão como relações reificadas entre as pessoas e relações sociais entre as coisas" (p.71).

A mercadoria só alcança o fetichismo graças à forma peculiar como é produzida na economia capitalista, isto é, na especificidade do trabalho alienado. Neste, o homem não domina a totalidade do processo produtivo, não só porque não é possuidor do produto final, mas também por não ter o domínio mental das diferentes etapas da produção. Ocorre com o processo de produção uma racionalização de tal ordem, que termina por fragmentá-lo inteiramente. O trabalhador nele se incorpora como uma parte mecanizada, como um outro objeto. ${ }^{3}$

Ao objetivar-se, ao aparecer socialmente na forma mercadoria, manifesta-se, concomitantemente, o aspecto desumano da sociedade capitalista. A reificação chega ao ponto de ser um dos elementos constituintes do capitalismo. Fragmentado como força de trabalho (quando se transforma em coisa), o homem também se fragmenta, de tal forma que a objetividade da mercadoria termina por expressar essa fragmentação. Em outras palavras, a mercadoria passa a reter uma unidade que não se encontra mais no homem, ou na relação de produção. Ela, por assim dizer, sintetiza o capitalismo, a propriedade privada e o trabalho alienado, pois se coloca como resultado e objetivo últimos das relações sociais. As relações entre os homens atingem uma forma racional e abstrata na mercadoria, um abstracionismo, contudo, originário do universo concreto da produção.

2 Marx expõe o caráter fetichista da mercadoria nos seguintes termos: "Porém, a forma mercadoria e a relação de valor dos produtos de trabalho, na qual ele se representa, não têm que ver absolutamente com sua natureza física e com as relações materiais que daí se originam. Não é mais nada que determinada relação social entre os próprios homens que para eles aqui assume a forma fantasmagórica de uma relação entre coisas. Por isso, para encontrar uma analogia, temos de nos deslocar à região nebulosa do mundo da religião. Aqui, os produtos do cérebro humano parecem dotados de vida própria, figuras autônomas, que mantêm relações entre si e com os homens. Assim, no mundo das mercadorias, acontece com os produtos da mão humana. Isso eu chamo fetichismo que adere aos produtos de trabalho, tão logo são produzidos como mercadorias, e que, por isso, é inseparável da produção de mercadorias" (1983, p.71).

3 Marx \& Engels, no Manifesto do Partido Comunista, de 1847, expõem nos seguintes termos a transformação do proletário em mercadoria: "El obrero, obligado a venderse a trozos, es una mercancía como otra cualquiera, sujeta, por tanto, a todos los cambios y modalidades de la concurrencia, a todas las fluctuaciones del mercado" (1961, p.79). 
O fetichismo aponta o caráter velado daquela aderência metafísica e teológica, que quer esconder suas marcas essenciais, efetivamente concretas, e encontra na forma de dinheiro a sua mais sublime efetivação. O invólucro místico da mercadoria manifesta-se, pois, no valor de troca. O uso tem interesse para os homens, mas somente a troca é que confere o estatuto último da coisa produzida, na forma de mercadoria, como relação social entre coisas, que são, igualmente, relações entre homens.

Para os objetivos deste trabalho, cabe, todavia, ressaltar que Marx empreendeu seus estudos tendo como base a produção material de bens. Não chegou a aplicar o conceito do fetichismo à instância cultural. A análise da cultura sob esse paradigma vai se dar no século XX, e talvez as reflexões dos teóricos da Escola de Frankfurt tenham sido as mais radicais nesse sentido (ainda que não haja unanimidade sobre o assunto entre Adorno e Benjamin, por exemplo). O que se pretende aqui é a averiguação das identidades e distinções entre mercadorias dadas à satisfação de necessidades físicas e imediatas e outras, eminentemente culturais e simbólicas, postas à disposição para suprir necessidades, pode-se dizer, da intuição, do desejo, da imaginação e da sensibilidade. O objetivo primordial deste trabalho é, portanto, o exame da transferência do conceito do fetichismo da mercadoria para a problemática da arte e da cultura. O problema artístico e cultural, nesse contexto, desloca-se das matrizes intrínsecas do seu fazer e estende-se até o circuito total de sua produção, reprodução e consumo. Isto é, já não se fala explicitamente de obra de arte, mas sim de uma mercadoria de natureza cultural, gerada de acordo com a lógica e os atributos industriais.

\section{2}

São por demais conhecidas as observações de Adorno \& Horkheimer (1985) acerca do caráter industrial que o capitalismo imprimiu à cultura no século XX e à sua imediata contrapartida, o consumo. ${ }^{4}$ A noção de indústria cultural, por ambos desenvolvida, não quer deixar margem à dúvida quanto à natureza intrínseca de seus propósitos. Contrariando a visão de cultura de massa, ambos os autores optaram por uma melhor estruturação conceitual, especialmente porque a noção de indústria cul-

4 Trabalhar-se-á aqui apenas com as análises acerca da indústria cultural, tal como aparecem na Dialética do esclarecimento. Adorno já havia aplicado o conceito de fetichismo na análise da música, em seu conhecido trabalho, "O fetichismo na música e a regressão da audição", de 1938, em resposta a Walter Benjamin e seu ensaio "A obra de arte na época de sua reprodutibilidade técnica", de 1936. Há duas versões deste ensaio, ambas traduzidas e editadas no Brasil: a primeira está na coletânea de textos de Benjamin, Magia e técnica, arte e politica. São Paulo: Brasiliense, 1985; a segunda versão apareceu pela primeira vez em A idéia do cinema, Rio de Janeiro: Civilização Brasileira, 1969, tendo sido posteriormente incluída na coleção "Os Pensadores", São Paulo: Abril Cultural, 1980, que traz também "O fetichismo", de Adorno. 
tural desfaz a pretensão ilusória de que se trata de uma cultura espontânea, que surge das massas. Os elementos diferenciais estão, de um lado, na noção prioritária do consumo que tal produção concomitantemente almeja e determina, contrariamente à imagem equivocada de criação das massas; e, de outro, no caráter efetiva e preponderantemente industrial que a cultura assumiu, vindo a se firmar como protótipo dominante de manifestação.

É igualmente sabido que tal proposição conceitual funda-se no choque e na desilusão, se se quiser, que os autores experimentaram diante do modelo cultural consumista da sociedade norte-americana, por força do exílio diante do nazismo. Tal prática de cultura em nada correspondia àquela função totalizante, de integração e recomposição do sujeito, tal como Lukács julgava adequado, e que tinha no romance do século passado a sua melhor expressão.

Desviando rapidamente do tema aqui proposto, cabe ressaltar que a tarefa de reconstruir, na imaginação e na subjetividade, uma totalização desalienante, diante de decomposição fragmentária do mundo objetual do trabalho, tarefa atribuída à arte por parte do filósofo húngaro, não encontrava mais terreno apropriado em nosso século. As iniciativas das vanguardas artísticas apontavam para outro rumo. A rejeição à poética emanada do realismo acentuava a renúncia de verossimilhança da relação da arte com a realidade, ou mesmo quando não renunciava (como foi o caso daqueles movimentos intimamente ligados com a política, particularmente os ocorridos na Rússia e na Alemanha), essa relação dava-se em um estágio diferenciado. De todo modo, a arte e a poética abandonaram a atitude contemplativa de uma composição orgânica, descobridora ou reveladora dos sentidos que escapam ao olhar, à percepção e à consciência usuais, para investir, mimeticamente, talvez, na fragmentação da vida a partir do interior da própria obra. É como se a vida e sua fragmentação tivessem adentrado definitivamente na criação, alojando-se explicitamente na obra - e este é o exato sentido do mimetismo na arte de vanguarda. A obra de arte procurou intencionalmente essa aproximação, como forma de desmascaramento daquele estilhaçamento que o capitalismo imprimia ao cotidiano e, principalmente, aos sujeitos sociais; leiase, às classes dominadas. ${ }^{5}$

Retornando à problemática da cultura no universo industrial, pode-se dizer que a mercadoria cultural, tal como outra qualquer, é resultado de um longo processo

5 Vale lembrar, a título de exemplificação, o intenso debate entre Lukács e Brecht acerca do realismo e do modernismo. Grosso modo, a acusação de formalismo à arte moderna, por parte de Lukács, devia-se à renúncia da arte de vanguarda àquela função restituidora da integralidade humana, talvez o último refúgio de recomposição do sujeito alienado e fragmentado, ou, se se quiser, último baluarte ao qual valia a pena apegar-se na tentativa de compreensão, ainda que individual e subjetiva, das múltiplas facetas do real. Por seu lado, Brecht acenava com o uso socialista de certas técnicas alcançadas pela arte modernista, particularmente a montagem e o distanciamento. Isto é, trazer a fragmentação para o interior da obra, em um primeiro momento, propiciaria uma identificação com o disperso, que seria quebrada com os efeitos de distanciamento, momento em que o espectador tomaria não só conhecimento do caos (por se ver nele inserido) e, ao distanciar-se, elaboraria modos de consciência e até de reação a essa fragmentação. Arte e práxis política estavam intrinsecamente ligadas. 
produtivo, cuja ênfase é o produto final, posto à venda, com base no valor de troca. Nesse processo intervém o trabalho humano em diversos âmbitos, alienado, dividido e fragmentado, a ponto de o produto não comportar mais as marcas dos diversos sujeitos que nele atuaram. O sujeito, nesse caso, é o trabalhador, coisificado abstratamente como força de trabalho. O artista-produtor é apenas uma parte dessa cadeia produtiva. A posse da produção quase sempre não lhe pertence, ainda quando restam porcentagens contratuais de direitos de autoria. O processo de produção deixa o âmbito preferencial da relação subjetiva e aloja-se na objetividade do complexo produtivo de bens (neste caso simbólico), e em suas complexas relações sociais. O trabalho e os produtos por ele gerados transformam-se em mercadorias, e, como se viu, estas são relações sociais, que assumem, no capitalismo, a forma de relações entre coisas. ${ }^{6}$

O processo geral, quando voltado para a geração de produtos, é fruto exclusivo da coisificação, quando o sujeito é incorporado nele como uma parte estilhaçada, quando não automatizada. Nesses termos, a equação do ato de fruir (talvez fosse preferível "usufruir") uma obra artística tem, como ponto de partida, a fragmentação de um processo reificado.

Ocorre, todavia, que a reificação original se propõe a estender-se até o destinatário. O consumidor relaciona-se com as experiências da sensibilidade a partir e por meio dos produtos dados pelas ofertas do mercado. Uma primeira conseqüência dessa cadeia de desenvolvimento redunda nos limites que se interpõem entre o consumidor e o próprio mercado. Nesse ponto devem ser relevadas as situações precisas de renda, estrutura concreta de distribuição dos produtos e, principalmente, evidências quanto ao gosto, aos valores e hábitos que são postos pela indústria da cultura. Em linguagem abstrata, pode-se dizer que, nesse exemplo, o sujeito só realiza seu prazer estético e só consegue satisfazer sua sensibilidade e emoção a partir dos objetos. Uma vez mais, a coisificação se faz presente. Desta feita, no momento terminal da cadeia.

O aparente sujeito destinatário, em última instância, é tão-somente um novo objeto na cadeia intrincada das relações produtivas para o mercado. Assim, a relação estabelecida pode ser sintetizada nos seguintes termos: ela vai do objeto ao sujeito, e este é encarado como um novo objeto. ${ }^{7}$ O sujeito destinatário não vai mais ao encontro

6 Com base no conceito de fetichismo de Marx, Georg Lukács analisou o ato de alhear-se do homem diante de sua atividade, diante do trabalho. Apontou a incidência do fenômeno tanto no plano objetivo, como no subjetivo. "Objetivamente, surge um mundo de coisas acabadas e de relações entre coisas (o mundo das mercadorias e do seu movimento no mercado). É verdade que os homens vão descobrindo as leis que regem tais objetos, mas, mesmo assim, estes contrapõem-se-lhes como outras tantas forças insuperáveis que geram o seu próprio poder. O indivíduo pode pois, com certeza, utilizar em seu proveito o conhecimento que tenha delas, sem que mesmo nesse caso lhe seja dado exercer, com a sua atividade, uma influência transformadora sobre o seu processar real. Subjetivamente, a atividade do homem - numa economia mercantil realizada - objetiva-se em relação a ele, torna-se numa mercadoria regida pela objetividade das leis sociais naturais estranhas aos homens e deve efetuar os seus movimentos tão independentemente dos homens como qualquer bem destinado à satisfação de necessidades, que se tornou coisa mercantil" (1974, p.101).

7 Adorno \& Horkheimer foram enfáticos na abordagem da questão da indústria cultural. O papel do destinatário nesse processo foi descrito nos seguintes termos: “O princípio impõe que todas as necessidades lhe sejam apre- 
de si, mas sim do produto. E o fato deste objeto destinar-se a suprir exigências e necessidades subjetivas não altera, aparentemente, os termos da equação, em um mundo no qual as exigências e necessidades são, também elas, interpostas pelos próprios mecanismos de mercado, terreno último e reino predileto do produto. ${ }^{8}$ Afinal, outras categorias de produtos, para consumo e satisfação de necessidades, são igualmente objetificadas e destinam-se a tantos outros sujeitos fragmentados. A crueza dos termos e elementos da equação traz, certamente, uma anulação do sujeito. Ela se dá tanto no nível daquele sujeito-operário que se transformou em simples força de trabalho, quanto no destinatário que é tomado pelo mercado somente como um consumidor. Em ambos os casos, os atributos do sujeito estão vilipendiados pela fragmentação incessante de uma trajetória que se origina na fabricação de produtos e termina em um sujeito, objeto da indústria cultural, não menos objetificado que o primeiro. Em outros termos: alguns poucos especialistas produzem, outros tantos não especialistas consomem. A relação entre ambos, contudo, é intermediada pelo produto, pelo objeto, a ponto de a relação só ser reconhecida socialmente no âmbito exclusivo da produção de mercadorias. A "desumanização" é parte integrante desse processo. ${ }^{9}$

Para Adorno \& Horkheimer, o caráter mercantil da obra de arte não é algo peculiar ao nosso século. A arte, neste século, vai acentuar (e esta é, no entender dos autores, a grande novidade) a negação de sua autonomia. Essa renúncia é acompanhada da redução da arte a mero bem de consumo. A partir de então, sua subordinação ao mercado é total, o que implica apresentar-se sempre como uma novidade para consumo, uma novidade, todavia, veladora da mesmice: a repetição e a exaustão são os protótipos daquilo que quer aparecer como novo e diferente.

O valor de troca, o lucro e a ênfase nos negócios vêm substituir todos os atributos da arte e suas grandes finalidades. A arte e seu âmbito não são mais espaços apropriados para o exercício e manifestação do juízo estético: transformaram-se em objetos preferencialmente destinados ao lazer e à diversão, uma extensão e continuidade da reificação dominante, mesmo quando apresentam-se como momentos de suspensão e de aparente distanciamento do dia a dia. A indústria da diversão e do lazer faz que a arte e a cultura se vejam integradas ao cotidiano alienante, concomitantemente como forma de fuga e de inserção. O processo industrial da cultura almeja a naturalização completa da reificação. O negócio e o lucro não são apenas intenções

sentadas como podendo ser satisfeitas pela indústria cultural, mas, por outro lado, que essas necessidades sejam de antemão organizadas de tal sorte que ele se veja nelas unicamente como um eterno consumidor, como objeto da indústria cultural" (1985, p.133).

8 Enfatiza-se, neste momento do texto, o aparentemente, pois, como se verá, há distinções entre mercadorias postas às necessidades materiais imediatas e as simbólicas, postas à disposição da sensibilidade, da intuição e da imaginação.

9 Segundo Lukács (1974, p.107), “O que, no seu destino, é típico da estrutura de toda a sociedade é que, ao objetivar-se e tornar-se mercadoria, uma função do homem manifesta com extremo vigor o caráter desumanizado e desumanizante da relação mercantil" (1974, p.107). 
da indústria cultural, mas princípios únicos. Sua ideologia é a sua própria forma, ou seja, a mercadoria.

Na concepção de Adorno \& Horkheimer, a possibilidade indiscriminada de consumo não aproximou as massas daquelas áreas das quais elas se viam excluídas: serviu, outrossim, para selar a decadência da cultura, ao reduzi-la unicamente à economia de mercado. Nas suas palavras:

Mesmo na flor da idade dos negócios, o valor de troca não arrastou o valor de uso como um mero apêndice, mas também o desenvolveu como o pressuposto de sua própria existência, e isso foi socialmente vantajoso para as obras de arte. A arte manteve o burguês dentro de certos limites enquanto foi cara. Mas isso acabou. Sua proximidade ilimitada, não mais mediatizada pelo dinheiro, às pessoas expostas a ela consuma a alienação e assimila um ao outro sob o signo de uma triunfal reificação. (1985, p.150)

Os autores da Dialética do esclarecimento aplicam com radicalidade o conceito da reificação ao universo da produção cultural industrializada. O imperativo do valor de troca provoca o obscurecimento do uso. ${ }^{10}$ A cultura é vista unicamente como mercadoria, ainda que se saliente o aspecto paradoxal de seu estatuto: "A cultura é uma mercadoria paradoxal. Ela está tão completamente submetida à lei da troca que não é mais trocada. Ela se confunde tão cegamente com o uso que não se pode mais usála. É por isso que ela se funde com a publicidade" (p.151).

\section{3}

A concepção da arte e da cultura exclusivamente como mercadoria parece desconsiderar certas particularidades que as fazem distintas daqueles bens voltados à satisfação de necessidades físicas. E isso se deve ao ponto de partida que Adorno e Horkheimer adotaram para a análise da obra de arte no âmbito industrial, qual seja, o do consumidor-objeto, que se complementa com o da indústria e seus interesses. Ambos os pólos se unem e são interdependentes. ${ }^{11}$

Se, no nível da abstração, é possível alcançar os limites da reificação, cabe, no entanto, detectar as peculiaridades que esse processo recebe quando se trata de bens materiais ou de bens simbólicos, como é o caso da produção cultural e artística (anteriormente, afirmou-se que na aparência não havia distinção entre produtos materiais

10 “O que se poderia chamar de valor de uso na recepção dos bens culturais é substituído pelo valor de troca; ao invés do prazer, o que se busca é assistir e estar informado, o que se quer é conquistar prestígio e não se tornar um conhecedor. O consumidor torna-se a ideologia da indústria da diversão, de cujas instituições não consegue escapar" (p.148).

11 Esse ponto de partida é o provocador da diferença de Adorno para com Benjamin e Brecht. Além desses pólos complementares (indústria-consumidor), Walter Benjamin e Bertolt Brecht colocam como elemento intrínseco e até privilegiado do fenômeno artístico e cultural a perspectiva do artista produtor, ao valorizarem a poética e o criador, dando relevância diferenciada aos mecanismos de produção, reprodução e consumo. Em suma, ambos operam com a possibilidade de transformação, ao passo que Adorno e Horkheimer descartam essa hipótese e contentam-se com a constatação do fenômeno com possibilidades ínfimas de ruptura. 
e simbólicos, postos ao consumo). A abstração empreendida, então, mostrar-se-á um necessário guia, porém incompleto se não se adentrar nas especificidades de cada tipo de produto. Do contrário, prevalece o imperativo da abstração. Se há uma unicidade quanto à compreensão do fenômeno, há, igualmente, uma diversidade quanto às especificidades dos produtos gerados. Ou seja, como valor de troca, os produtos culturais não se distinguem dos materiais, pois ambos têm a mesma origem e resultam de um idêntido processo reificado. Contudo, no que se refere ao uso, há diferenciações que necessitam ser acentuadas. A produção material, em princípio, destina-se à satisfação de necessidades de sobrevivência e de bem-estar; a simbólica, à satisfação do gosto, do prazer estético e do desejo.

Por mais que se proceda à análise das obras de cultura sob o paradigma da mercadoria, há que ressaltar que elas dirigem-se para a satisfação de necessidades sensitivas, intuitivas e da imaginação, para além, portanto, das físicas. O trabalho nas artes, nos atos de cultura, não é unicamente demonstração de uma habilidade técnica, com vistas a um valor de troca no seio da realidade de mercado. Com efeito, ele atinge um patamar que o trabalho mercantil, de produtos materiais, de um modo geral, não alcança, qual seja, o da beleza. Ainda que a arte não perca seu vínculo com as técnicas de produção, dada a historicidade de suas formas, ela não se contenta em restringir-se a elas. A produção cultural não é necessariamente utilitária. A transformação da matéria e a conexão entre forma e conteúdo, mesmo que fundadas em tempos históricos precisos, não se contentam com a atitude mimética, como um simples reflexo do mundo objetivo. Antes de mais nada, a criação é exercício deliberado da capacidade humana de buscar formas sensiveis que procuram a beleza, em última instância, e, assim, sobrepor-se ao seu próprio tempo. Apesar da distância temporal, a tragédia grega mantém seu devido atrativo sobre a contemporaneidade. ${ }^{12}$ Os atos culturais são representações que nascem das relações de produção e contribuem para a sua reprodução e transformação. Isto é, carregam um potencial utópico quando imaginam e criam possibilidades de outras relações.

Ainda que inserida no processo da mercantilização, a prática da arte e da cultura mantém uma certa distância para com o trabalho coisificado, próprio do universo fabril das mercadorias. Não se presta, única e somente, aos valores de troca que refletem a alienação generalizada. Apesar de relacionarem-se e, sob certo aspecto, estarem dependente das condições sociais e econômicas alienantes, as criações artísticas podem direcionar-se para o futuro, num processo de nítida negação, e manifestar a vontade e a liberdade, diante de um cotidiano de desilusão. ${ }^{13}$

12 Cabe lembrar, a esse respeito, a visão de Karl Marx sobre as artes e a literatura, nada complacente com a versão oficial do marxismo da Segunda Internacional. A esse respeito, consultar Lunn, 1986, p.19-45.

13 "Según Marx, el mejor arte desempeña la función cognoscitiva de penetrar a través de las nubes ideológicas que oscurecen las realidades sociales. Además, al materializar gráficamente esta relativa libertad frente al mero reflejo de las circunstancias externas, las creaciones estéticas podían desarrollar el deseo de una libertad mayor frente a una sociedad deshumanizada y alienante. Todo arte tiene capacidad para crear una necesidad de disfrute y 
Os processos artísticos e culturais não se reduzem, imediata e sumariamente, à concepção do trabalho alienado, tal como aplicado na relação capitalista de produção. A superação da alienação está presente na arte (ou também em outras atividades, tais como na ciência e na filosofia), se esta assim o quiser, possibilitando o desenrolar de um lado utópico e crítico, de exploração das faculdades humanas para além das atividades fundantes da produção econômica. Sua autonomia, portanto, deve ser preservada, mesmo que se entenda que esta circunscreve-se, em última medida, ao desenrolar geral do processo social. Ela possibilita a vivência sensorial e aprofunda a percepção das complexidades históricas. A arte e a cultura estão, neste século, inseridas no universo econômico, como atividade de exploração e expansão do capital, e participam também do universo simbólico como um dos mecanismos privilegiados de sedimentação do imaginário dominante. Os meios preferenciais de exercício da hegemonia são os veículos de difusão da informação e da cultura de massas.

Entretanto, ainda que diferenciando-se em sua destinação (como uso, portanto) dos produtos materiais, a obra de arte mantém-se em um patamar de extrema delicadeza quando discutida no nível ideológico. Por destinar-se à beleza e à satisfação da subjetividade, ela torna-se um elemento conformador do imaginário. Mas, como ideologia, nada assegura que será eterna e completamente reiterativa da ordem dominante; isto é, ela pode dar-se em uma configuração de contra-hegemonia. Ela pode ser crítica, ainda que ocorra por intermédio da indústria da cultura e se manifeste por intermédio dos meios de comunicação de massa. Se o capitalismo faz uso da arte e da cultura para solidificar o conjunto social, há que relevar que ele não detém o domínio pleno e absoluto do ato de criação, embora detentor dos meios de produção da arte dominante. É igualmente sabido que a vida em sociedade funda-se na oposição de classes, que, por sua vez, deixa transparecer suas marcas nas grandes obras, em grandes atos de cultura. Essa trans-aparência restitui o aspecto crítico da arte e da cultura, mesmo em suas formas massificadas. ${ }^{14}$

No domínio da propriedade privada e do trabalho alienado, a mercadoria, como tal, é uma espécie de alegoria fechada e acabada do capitalismo. Os bens culturais, por sua vez, são veículos que repõem essa alegorização, mas não somente isso: mesmo escamoteando, eles restituem aos sujeitos sociais a dominação e sua contrapar-

educación estéticos que la sociedad capitalista no puede satisfacer. Aunque cada vez cae en mayor medida bajo la influencia del mercado, el arte se produce y consume en relativa autonomía y no es idéntico al trabajo fabril ni a una mercancía pura. Ningún escritor estaba más consciente que Balzac del valor monetario de su arte, pero en las novelas de Balzac vieron Marx y Engels el retrato más fiel e histónicamente rico de la sociedad francesa de 1815-1848" (Lunn, 1986, p.27).

14 Neste momento, é bom não deixar no esquecimento a ponderação de Walter Benjamin acerca do cinema: "Enquanto o capitalismo conduz o jogo, o único serviço que se deve esperar do cinema em favor da revolução é o fato de ele permitir uma crítica revolucionária das concepções antigas de arte. Não contestamos, entretanto, que, em certos casos particulares, possa ir ainda mais longe e venha a favorecer uma crítica revolucionária das relações sociais, quiçá do próprio princípio da propriedade" (1980, p.18). Em um outro registro, muitos exemplos poderiam ser arrolados que salientam essa hipótese. No caso brasileiro, vale pontuar a forte presença da televisão, particularmente dos festivais de música da Record, no final dos anos 60 e início da década de 1970, que incentivaram sobremaneira a reação à ditadura militar. 
tida, a possibilidade da mudança e da transformação. A arte e a cultura são alegorias em aberto, que se prestam à valorização dos atributos subjetivos diante da reificação e repõem ao corpo social os seus limites, bem como algumas possibilidades de superação.

Assim, não parece adequado reduzir toda a produção cultural da época da economia de mercado a produtos de mercado. Ela se tornou dominante graças à configuração industrial e empresarial que essa prática vem adotando nas últimas décadas. Mas, ao lado dela, outras tantas relações ainda permanecem vivas, desde as artesanais, levadas a efeito por produtores independentes, que põem à venda as suas obras, até as patronais, sem fins lucrativos, mantidas por instituições privadas ou públicas, ou mesmo as govemamentais, em que as práticas culturais desenrolam-se no interior de instituições estatais, ou a partir delas. Esses casos não podem ser classificados como uma prática da indústria cultural, embora possa ocorrer que terminem em produtos que se dão à venda. Os produtos, contudo, são diferenciados, sem a pretensão massiva e consumista que adquirem no caso industrial. Essas práticas ainda se consubstanciam, conforme o caso, ou na esfera das práticas culturais populares, ou na erudita.

\section{4}

Ao se enfatizar a presença de outros modos de práticas culturais na época contemporânea pretende-se apenas ressaltar a pluralidade diante da hegemonia e do pretenso império industrial. Essa pluralidade torna-se de maior valia quando aplicada a casos como o Brasil. Aqui, o modelo exercitado pela indústria cultural não chega a compor o quadro simbólico geral; isto é, não constitui um universo homogêneo, ainda que sua pretensão seja esta. O caso brasileiro não pode ser comparado irrestritamente aos países europeus do capitalismo clássico, ou mesmo à sociedade norte-americana de alto consumo. Neles, a divisão do trabalho solidificou a distância entre artistas e não-artistas, criando categorias profissionais e campos de trabalho especializados na produção cultural, tanto erudita como, e principalmente, industrial.

No Brasil, o acesso aos bens materiais e simbólicos restringe-se a camadas sociais especificas, restando às classes populares limites acentuados, em constante conflito com os desejos que o próprio mercado alimenta, mas que as condições econômicas e sociais impedem de serem satisfeitos. Para o caso dos bens culturais, na lógica de mercado, a distribuição de renda é um dos fatores determinantes do tipo de produto que pode ser mais facilmente adquirido. O mercado dos bens simbólicos obedece à mesma dinâmica do material, sendo determinado pela desigualdade da distribuição da riqueza, com o agravante da fragilidade do sistema educacional que, além de não ser extensivo a todas as classes, alimenta um ideário simbólico próprio da cultura erudita e da cultura massificada, desprezando, quase que completamente, os modos de constituição e exercício das culturas populares, que se fazem presentes até mesmo nos grandes centros urbanos. Portanto, não ocorre aquele acesso indiscriminado e intensivo das massas à cultura industrial, mas tão-somente a uma parte dela. 
É bastante sintomático que as cidades industrializadas, ainda hoje, apresentem formas culturais oriundas da vida rural. Elas não foram eliminadas pela cultura industrial, nem ao menos assimiladas pelos veículos de comunicação de massa. No contexto geral da cidade, elas não almejam resgatar o passado dos migrantes, mas tão-somente colocar-se como contraponto à massificação do cotidiano. No mínimo, restituem aos seus praticantes o deslocamento da condição urbana e, nesse aspecto, apontam para a condição de desqualificados sociais, já que o imperante é o consumo de bens. Ora, essas práticas não se constituem bens culturais. Não sobrevivem, por outro lado, como resíduo de um passado belo, mas unicamente como forma dominada e diferenciada de uma possibilidade social e cultural.

A análise do campo simbólico em um país como o Brasil não pode apenas orientar-se pela oposição cultura erudita/indústria cultural. A presença dos excluídos socialmente dos mercados materiais e simbólicos torna relevante, para a prática da cultura, o papel das culturas populares, também excluídas do modelo simbólico dominante, tanto erudito como industrial. ${ }^{15}$

A cultura erudita alimenta e reitera um código específico, destinado a um público restrito, educado e iniciado na apreensão de seu universo. Os meios de expansão e de imposição de seu campo simbólico estão ao encargo dos sistemas de educação e das instituições culturais depositárias deste patrimônio, particularmente os museus e, em graus diferenciados, os edifícios teatrais, quando se voltam à difusão da alta cultura. A intenção dominante da indústria cultural é a indiferenciação de todas as culturas, querendo, com isso, suplantar as diferenças culturais, sociais e ideológicas. Seu mecanismo de manifestação dá-se no interior de uma estrutura empresarial de mercado e de concorrência, pela divisão entre produtores especialistas, de um lado, e público consumidor, de outro, intermediados pelos veículos de distribuição, dentre os quais os meios de comunicação de massa são os preferenciais.

As formas culturais populares, por seu turno, não se portam como espetáculos postos à venda, nem ao menos almejam sobrepor-se como formas dominantes de cultura. Não contam com nenhum espaço institucional para reiterar os seus valores. Os seus praticantes estão inseridos na condição de dominados da prática mercantil de que a dominação cultural alardeia.

A diferenciação dos modos de prática cultural a que se assiste em um país como o Brasil, a despeito de todo o império da cultura sob moldes industrializados, não tem a pretensão de isolar formas estamentais de manifestação. As inter-relações políticas e ideológicas entre esses modos são por demais complexas para que se possa contentar com um purismo conceitual que, em realidade, não se vê. A diferenciação entre

15 Adotam-se, aqui, parcialmente, as análises de Alfredo Bosi (1992, p.308-76) e Néstor García Canclini (1983, p.1741). De Alfredo Bosi, a pluralidade cultural e suas diversas relações, particularmente as que se estabelecem entre a cultura popular e as culturas de massa e a erudita; de García Canclini, a análise das desigualdades culturais e a ilusão de que todos desfrutam a superioridade da cultura dominante, apesar das distâncias entre as classes sociais no tocante à propriedade e ao domínio dos meios de produção. 
formas dominantes e dominadas tem o único propósito de trazer à tona a pluralidade de formas culturais que, bem se sabe, influenciam umas às outras. A ênfase na diferenciação e na diversidade quer apenas fazer ver a pertinência e a complexidade da análise da cultura e, por extensão, das políticas culturais em países como o Brasil. As formas de aparição do sensivel, de manifestação da intuição e da imaginação criadoras, de realização da beleza e do prazer estético são por demais complexas (quando não, interdependentes), para se verem condicionadas e reduzidas à categoria de mercadoria e seu fetichismo. Estas noções são, por certo, da maior valia quando aplicadas ao mecanismo industrial de produção da cultura, mas somente neste contexto é que se fazem pertinentes. Outras práticas necessitam de outros aportes teóricos.

BOLOGNESI, M. F. The cultural commodity. Trans/Form/Ação (São Paulo), v.19, p.75-86, 1996.

- ABSTRACT: Adomo and Horkheimer adoted the notion of the fetishism of commodities for the analysis of art and culture. Material, physical goods are not identical to symbolic ones. In spite of being predominant cultural industry can not be taken as the prototype of all analyses of culture. One can not reduce all cultural productives of the period of market economy to market products. The plurality of artistic and cultural practices present in countries like Brazil, does make questionable the indiscriminate use of the Frankfurtian framework.

- KEYWORDS: Commodity; fetishism; cultural industry; cultural goods.

\section{Referências bibliográficas}

ADORNO, T. W., HORKHEIMER, M. Dialética do esclarecimento: fragmentos filosóficos. Rio de Janeiro: Zahar, 1985.

BENJAMIN, W. et al. Textos escolhidos. São Paulo: Abril Cultural, 1980. (Col. Os Pensadores). BOSI, A. Dialética da colonização. São Paulo: Cia. das Letras, 1992.

CANCLINI, N. G. As culturas populares no capitalismo. São Paulo: Brasiliense, 1983.

LUKÁCS, G. Histónia e consciência de classe. Porto: Escorpião, 1974.

LUNN, E. Marxismo y modemismo. Un estudio histórico de Lukács, Brecht, Benjamin y Adorno. México: Fondo de Cultura Económica, 1986.

MARX, K. O capital: crítica da economia política. São Paulo: Abril Cultural, 1983. v.1. (Col. Os Economistas).

MARX, K., ENGELS, F. Biografia del Manifesto Comunista. México: Cia. General de Ediciones, 1961. 